\title{
Pharyngeal Airway Volume as a Predictor of the Efficacy of Obstructive Sleep Apnea Treatment with a Mandibular Advancement Device
}

Thais Moura Guimaraes ${ }^{1}$, Otávio Ferraz ${ }^{2}$, Rowdley R. Pereira Rossi ${ }^{3}$, Paulo Afonso Cunali², Luciana Oliveira e Silva², Cauby M. Chaves Júnior ${ }^{4}$, Cibele Dal-Fabbro ${ }^{2}$, Milton Maluly², Lia Bittencourt ${ }^{5}$, Sérgio Tufik ${ }^{6}$

\section{Abstract}

Background: The efficacy of mandibular advancement devices (MAD) in the treatment of obstructive sleep apnea (OSA) varies widely among patients, and at present it is difficult to predict success. Previous studies have shown a relationship between a gain in pharyngeal volume with MAD in situ and the success of the treatment. The aim of this study was to evaluate this change in volume of the upper airway using cone beam computed tomography (CBCT), measured at a baseline of maximum intercuspation (TO) and at maximum protrusion (T1) using a George Gauge to simulate a MAD produced protusion, and investigate whether this change in volume can be used to predict success with MAD.

Methods and Findings: 10 individuals with mild/moderate OSA underwent CBCT at baseline (TO - maximum intercuspation) and time 1 (T1 - maximum protrusion using a George Gauge for bite registration). All patients then underwent polysomnography before and after MAD treatment. The total volume, total area and minimal cross section area of the pharynx were then analyzed again by CBCT. The mean of the protrusive position using a George Gauge at baseline $(12.2 \mathrm{~mm} \pm 1.9)$ was similar to the maximum comfortable position achieved with MAD $(11.6 \mathrm{~mm} \pm 2.08)$. MAD treatment significantly reduced the Apnea Hypopnea Index (AHI) values (11.7 \pm 6.7 to $2.4 \pm$ 3.1) $(p=0.01)$. The retropalatal volume increased significantly between T0 and T1 (6240 $\mathrm{mm}^{2} \pm 2224$ to $\left.7720 \mathrm{~mm}^{2} \pm 3516\right)(p=0.04)$. Changes in volume measured by CBCT (T1-T0) were positively predictive for changes in $\mathrm{AHI}$ (initial-final) ( $p=0.05$ ).
1 DDS, MSc, PhD student, Departmento de Psicobiologia, *

2 DDS, MSc, Research at the Sleep Medicine and Biology Division, Departmento de Psicobiologia, *

3 DDS, MSc, PhD, Research at the Sleep Medicine and Biology Division, Departmento de Psicobiologia, *.

4 DDS, MSc, PhD, Associate Professor, Division of Orthodontics and Pediatric Dentistry, Department of Clinical Dentistry, Federal University of Ceará, *

5 DDS, MSc, PhD student, Departmento de Pneumologia, *

6 MD, MSc, PhD, Adjunct Professor, Departmento de psicobiologia, *

*: Universidade Federal de São Paulo, Brazil.

Contact information:

Thais Moura Guimaraes.

झ thaisdemouraguimaraes@gmail.com 
Conclusion: Variations in CBCT volume of the upper airway, at baseline and using bite registration at maximum comfortable protrusion, was a predictor for a reduced apnea/hypopnea index after treatment with MAD.

\section{Keywords}

CBCT, Predictor, Oral

Appliance, Sleep Apnea,

Obstructive.

\section{Introduction}

Obstructive sleep apnea (OSA) is a respiratory sleep disorder that produces hypoxemia and sleep fragmentation [1]. Craniofacial alterations in the skeletal and soft tissue around the pharynx have been associated with OSA [2].

Mandibular advancement device (MAD) treatment modifies the position of the jaw and consequently increases the anteroposterior, laterolateral and minimal cross section area of the pharyngeal airway [3-6].

MAD treatment has good compliance [7], but its success varies among patients: about $66.7 \%$ to $80.6 \%$ in mild OSA, and $33.3 \%$ to $65.2 \%$ in moderate OSA, considering success as when there is an $\mathrm{AHI}$ of $>5[8,9]$.

Therefore, studies have tried to find a way to identify patients who are more indicated to use MAD [10]. Although variables such as AHI, body mass index (BMI) and age have been suggested as factors that can predict success, clinical prediction is still uncertain [11]. Thus, the aim of this study was to evaluate the change in volume of the upper airway using cone beam computed tomography (CBCT), measured at a baseline of maximum intercuspation (TO) and at maximum comfortable protrusion (T1), using a George Gauge for bite registration to simulate the effect of MAD treatment, to try to predict whether differences in the change in this volume could be used to predict the success of the treatment.

\section{Methods}

10 patients with mild to moderate OSA attending the ambulatory dental clinic of the Associação de Fundo de Investimento à Pesquisa (AFIP) were selected.

The inclusion criteria were: an $\mathrm{AHI}$ between 5 and 30 , male or female, $\mathrm{BMI} \leq 35 \mathrm{Kg} / \mathrm{m}^{2}$, aged 18 to 65 years and a protrusion larger or equal to $7 \mathrm{~mm}$. Exclusion criteria were: active periodontal disease, extensive caries, insufficient teeth, predominantly central apneas, use of psychoactive drugs, clinical disease, and other sleep disorders.

All patients signed an informed consent and the protocol was approved by the Ethics Committee of the Universidade Federal de São Paulo (UNIFESP).

Volunteers completed baseline orthodontic documentation consisting of cone beam computed tomography $(C B C T)$, cast models and frontal, profile and intraoral photographs.

All patients underwent a dental impression and bite registrations with the George Gauge ${ }^{\circledR}$. The bite registration recorded with the George Gauge at the $50 \%$ position of maximum mandibular advancement was used for the MAD construction. Another bite registration with the George Gauge on maximum comfortable protrusion was used to perform the $\mathrm{CBCT}$, simulating the final MAD protrusion. All volunteers underwent CBCT at baseline (TO) (at maximum intercuspation) and with bite registration with the George gauge at maximum comfortable protrusion (T1).

The MAD used was the Brazilian Dental Appliance (BRD) [12], and the progressive mandibular ad- 
vancement made by percentage until the maximum comfortable protrusion (final position) was reached. Before and after treatment, all patients underwent polysomnography.

\section{Polysomnography}

The full-night polysomnography (PSG) was done at AFIP's Sleep Institute using a digital polysomnograph (Embla N7000, Embla Systems, Inc., Broomfield, CO, USA). Breathing was monitored with nasal cannula and thermistor, respiratory effort was evaluated by inductance plethysmography in the chest and abdomen. For sleep staging, respiratory events (recommended rule), arousals and periodic leg movements the American Academy of Sleep Medicine (AASM) criteria were used [13].

\section{CBCT}

All volunteers were positioned seated with the Frankfurt plane parallel to the ground and the mid-sagittal plane perpendicular to the ground. The images were obtained using i-CA ${ }^{\circledR}$ equipment (Imaging Sciences International, Hatfield, PA, USA). The field-of-view (FOV) was $22 \mathrm{~cm}$, voxel $0.4 \mathrm{~mm}$, peak kilovoltage $(K V P)=120$, exposure time of 30 seconds, without use of a chin cup, but the head was fixed with a brace in the forehead region. The CBCT included the glabella and the entire $4^{\text {th }}$ cervical vertebra. Volunteers were asked not to swallow or move during the examination. They were also requested to remove any jewelry or metal objects and any intraoral prosthesis from the oral cavity. The exam included the upper airway, including the nasal cavity, nasopharynx, oral cavity, oropharynx and laryngopharyngeal airway. The radiation dose was $104.5 \mathrm{mSv}$ (micro Sieverts) in line with the ICRP (International Commission on Radiological Protection) protocol of 2005. The software Dolphin Imaging ${ }^{\circledR}$ 3-D (version 11.7, Dolphin Imaging Solutions, Chatsworth, (A) was used to process and manipulate the volumetric data obtained from the DICOM file (Digital Imaging and Communications in Medicine).
The total volume, total area and minimal cross section area of the pharynx were analyzed. The upper limit of the pharynx was defined as the horizontal line $\mathrm{H} 1$, the posterior nasal spine (PNS) at the lower edge of basion point (BA), and the lower limit $\mathrm{H}_{2}$ as the lower edge of the cervical vertebra $\mathrm{C} 4$. The total volumes of the retropalatal region (between the palatal plane and the lower edge of the uvula), the retrolingual region (between the lower edge of the uvula and the upper most edge of the epiglottis) and the hypopharynx (between the uppermost edge of the epiglottis and the lower edge of the cervical vertebra (4) were analyzed.

\section{Statistical analysis}

The analysis was performed using SPSS software, version 18, and descriptive analyzes of the data are presented as mean and standard deviation. Wilcoxon test was used for pre and post treatment evaluation. Univariate linear regression was performed using $\mathrm{AHI}$ variation (between baseline and after treatment) and the delta of CBCT volume variation (CBCT taken at maximum protrusion (T1) using the George Gauge for bite registration and CBCT at a baseline of maximum intercuspation (TO).

\section{Results}

The sample comprised 10 individuals. Ninety percent of the sample were women, aged $54 \pm 7$ years with a BMI of $24.7 \pm 3.4 \mathrm{~kg} / \mathrm{m}^{2}$. The mean of protrusive position on the George Gauge at CBCT was similar to the maximum comfortable position with MAD. The baseline characteristics are shown in Table 1.

Table 1. Baseline characteristics .

\begin{tabular}{|l|c|}
\multicolumn{1}{|c|}{ Anthropometry } & Sample $(\mathbf{n = 1 0})$ \\
\hline Gender (men \%)\# & $10 \%$ \\
\hline Age (years) & $54 \pm 7$ \\
\hline BMI $\left(\mathrm{kg} / \mathrm{m}^{2}\right)$ & $24.7 \pm 3.4$ \\
Protrusion on George Gauge $(\mathrm{mm})$ & $12.2 \pm 1.9$ \\
\hline Protrusion on MAD $(\mathrm{mm})$ & $11.6 \pm 2.08$ \\
\hline
\end{tabular}

Mean and standard deviation, \#: relative frequency. 
Treatment with MAD changed AHI by $9.3 \pm 6.4$. Considering the strict success criteria of a $50 \%$ drop in $\mathrm{AHI}$ associated with an $\mathrm{AHI} \leq 5$, our sample showed an 80\% success rate. Table 2 shows polysomnography characteristics before and after treatment.

Table 3 shows the baseline CBCT values and CBCT values on bite registration at maximum comfortable

Table 2. Polysomnography characteristics.

\begin{tabular}{|l|c|c|c|}
\multicolumn{1}{|c|}{ Variables } & Before MAD & After MAD & p \\
\hline Sleep latency & $14.4 \pm 9.4$ & $16.3 \pm 16.0$ & 0.88 \\
\hline REM latency & $94.7 \pm 30.5$ & $77.3 \pm 33.6$ & 0.29 \\
\hline Sleep Efficiency & $82.31 \pm 4.98$ & $83.2 \pm 6.38$ & 0.65 \\
\hline N1 & $9.6 \pm 5.7$ & $6.7 \pm 3.9$ & 0.20 \\
\hline N2 & $42.3 \pm 8.4$ & $49.9 \pm 8.6$ & 0.07 \\
\hline N3 & $27.8 \pm 8.3$ & $24.1 \pm 9.5$ & 0.17 \\
\hline REM & $20.3 \pm 3.9$ & $19.4 \pm 3.8$ & 0.51 \\
\hline Arousal index & $21.8 \pm 8.0$ & $11.1 \pm 3.4$ & 0.01 \\
\hline AHI & $11.7 \pm 6.7$ & $2.4 \pm 3.1$ & 0.01 \\
\hline Apnea index & $4.4 \pm 4.4$ & $0.8 \pm 1.1$ & 0.02 \\
\hline Hypopnea index & $7.3 \pm 4.7$ & $1.6 \pm 2.6$ & 0.01 \\
\hline Media saturation & $95.2 \pm 1.8$ & $95.4 \pm 1.7$ & 0.61 \\
\hline Lowest saturation & $87.1 \pm 3.7$ & $89.9 \pm 3.0$ & 0.04 \\
\hline
\end{tabular}

Mean and standard deviation, Wilcoxon test, $*$ : $p<0.05$.

Table 3. Tomographic characteristics.

\begin{tabular}{|c|c|c|c|}
\hline Variables & Baseline & $\begin{array}{l}\text { Bite } \\
\text { registration }\end{array}$ & p \\
\hline $\begin{array}{l}\text { Total Volume } \\
\left(\mathrm{mm}^{3}\right)\end{array}$ & $13692 \pm 4324$ & $14656 \pm 138$ & 0.65 \\
\hline $\begin{array}{l}\text { Retropalatal } \\
\text { volume }\left(\mathrm{mm}^{3}\right)\end{array}$ & $6240 \pm 2224$ & $7720 \pm 3516$ & 0.04 \\
\hline $\begin{array}{l}\text { Retrolingual } \\
\text { volume }\left(\mathrm{mm}^{3}\right)\end{array}$ & $3156 \pm 1171$ & $3361 \pm 1966$ & 0.58 \\
\hline $\begin{array}{l}\text { Hypopharynx } \\
\text { volume }\left(\mathrm{mm}^{3}\right)\end{array}$ & $3938 \pm 1646$ & $3399 \pm 2479$ & 0.39 \\
\hline $\begin{array}{l}\text { Minimal Cross } \\
\text { Section }\left(\mathrm{mm}^{2}\right)\end{array}$ & $98 \pm 40$ & $94 \pm 68$ & 0.29 \\
\hline $\begin{array}{l}\text { Retropalatal area } \\
\left(\mathrm{mm}^{2}\right)\end{array}$ & $272 \pm 74$ & $269 \pm 75$ & 0.96 \\
\hline $\begin{array}{l}\text { Retrolingual area } \\
\left(\mathrm{mm}^{2}\right)\end{array}$ & $152 \pm 51$ & $153 \pm 73$ & 0.96 \\
\hline $\begin{array}{l}\text { Hypopharynx } \\
\text { area }\left(\mathrm{mm}^{2}\right)\end{array}$ & $195 \pm 64$ & $152 \pm 87$ & 0.17 \\
\hline
\end{tabular}

protrusion. Only retropalatal volume increased significantly between basal CBCT and bite registration at maximum comfortable protrusion.

There was no correlation between baseline $\mathrm{AHI}$ and baseline total CBCT volume $(p=0.68)$, and there was no correlation between $A H I$ after MAD and total CBCT volume with bite registration at maximum comfortable protrusion $(p=0.14)$. However in the univariate linear regression, delta $C B C T$ volume (CBCT volume with bite registration at maximum comfortable protrusion/CBCT volume at baseline at maximum intercuspation) was a predictor of changes in $\mathrm{AHI}(\mathrm{AHI}$ baseline - $\mathrm{AHI}$ with MAD) $\mathrm{p}=$ 0.03, with $R^{2}=0.46$, Beta $=0.679$, Durbin Watson $=1.709$

\section{Discussion}

This is an important study because it is the first to our knowledge to investigate pharyngeal airway volume using CBCT with and without bite registration in maximum protrusion as a predictor of the success of MAD. In our study, individuals with a higher volume delta (T1-T0) showed a greater reduction in $\mathrm{AHI}$.

Several studies have demonstrated increased pharyngeal volume as a result of therapies with MAD using volumetric imaging $[3,5,6,14-20]$, but few studies have used this change in the pharynx (MAD in situ and baseline) as a predictor of success, or compare these changes in MAD responders and non-responders.

In respect of these studies, there is controversy about volume predicting success. Although most studies have found a relation between changes in pharynx size after MAD and AHI changes Sam et al. (2006) found no significant correlation between changes in $\mathrm{AHI}$ and changes in upper airway variables using computed tomographic in 23 individuals. Sutherland et al. (2011) did not find any relation between changes in $\mathrm{AHI}$ and changes in airway volume or between respon- 
ders and non responders in 18 individuals who had undergone magnetic resonance imaging. However, Gao et al. (1999) found a positive association between changes in $\mathrm{AHI}$ and increased upper oropharynx area after MAD in eleven individuals using magnetic resonance imaging. Chan et al. (2010) showed increases in size in the upper airway after treatment with MAD only in responders $(\geq 50 \%$ reduction in $\mathrm{AHI})$ in 69 individuals using magnetic resonance imaging. Ogawa et al. (2015) found responders ( $\geq 50 \%$ reduction in $\mathrm{AHI}$ ) decreased in relation to tongue length with MAD using magnetic resonance imaging in 68 individuals. Lee et al. (2010) showed retropalatal space increased in the responders, in 76 individuals using lateral cephalometry.

Our study used CBCT with a bite registration at maximum comfortable protrusion to try to simulate a MAD produced protrusion. It is interesting for clinical practice because it can help in the decision to use MAD treatment or not, and save time and reduce by not carrying out ineffective MAD treatment. In our study, there was a correlation between an increase in $\mathrm{CBCT}$ volume of the upper airway with bite registration and a drop in $\mathrm{AHI}$.

\section{Conclusion}

The delta of the variation in the volume of the upper airway measured using CBCT between baseline at maximum intercuspation and at maximum comfortable protrusion, using a George Gauge to simulate the effect of MAD treatment, was a predictor for a greater decrease in apnea/hypopnea index.

\section{Limitations}

Ours work have some limitations as the number of cases was small and they were milder cases.

\section{Acknowledgments}

Associação de Fundo à Pesquisa, FAPESP and CAPES

\section{Funding}

Associação de Fundo à Pesquisa, FAPESP, CAPES

\section{Competing and conflicting interests}

We do not have any conflicts of interest

\section{References}

1. AASM. The International Classification of Sleep Disorders: diagnostic and coding manual. Westchester: American Academy of Sleep Medicine; 2005.

2. Sutherland K, Lee RW, Cistulli PA. Obesity and craniofacial structure as risk factors for obstructive sleep apnoea: impact of ethnicity. Respirology. 2012; 17(2):213-22.

3. Kyung SH, Park YC, Pae EK. Obstructive sleep apnea patients with the oral appliance experience pharyngeal size and shape changes in three dimensions. Angle Orthod. 2005; 75(1):15-22.

4. Lee $\mathrm{CH}$, Kim JW, Lee HJ, Seo BS, Yun PY, Kim DY, et al. Determinants of treatment outcome after use of the mandibular advancement device in patients with obstructive sleep apnea. Arch Otolaryngol Head Neck Surg. 2010; 136(7):677-81.

5. Kaur A, Chand P, Singh RD, Siddhartha R, Tripathi A, Tripathi $S$, et al. Computed tomographic evaluation of the effects of mandibular advancement devices on pharyngeal dimension changes in patients with obstructive sleep apnea. Int J Prosthodont. 2012; 25(5):497-505.

6. Chan AS, Sutherland K, Schwab RJ, Zeng B, Petocz P, Lee RW, et al. The effect of mandibular advancement on upper airway structure in obstructive sleep apnoea. Thorax. 2010; 65(8):72632.

7. Kushida CA, Morgenthaler TI, Littner MR, Alessi CA, Bailey $D$, Coleman J, et al. Practice parameters for the treatment of snoring and Obstructive Sleep Apnea with oral appliances: an update for 2005. Sleep. 2006; 29(2):240-3.

8. Dieltjens $M$, Vanderveken $O M$, Hamans $E$, Verbraecken JA, Wouters K, Willemen $M$, et al. Treatment of obstructive sleep apnea using a custom-made titratable duobloc oral appliance: a prospective clinical study. Sleep Breath. 2013; 17(2):565-72.

9. Raunio A, Mattila $P$, Huuskonen $U$, Oikarinen $K$, Sándor GK. The influence of a mandibular advancement plate on polysomnography in different grades of obstructive sleep apnea. J Oral Maxillofac Res. 2015; 6(1):e4.

10. Pliska BT, Almeida F. Effectiveness and outcome of oral appliance therapy. Dent Clin North Am. 2012; 56(2):433-44.

11. Cuccia AM, Caradonna C. Mandibular advancement devices: indications and predictors of treatment outcome. A review. Minerva Stomatol. 2007; 56(9):427-43. 
12. Dal-Fabbro C JC, Bittencourt LRA, Tufik S. Clinical and polysomnographic assessment of the BRD Appliance in the treatment of Obstructive Sleep Apnea Syndrome. Dental Press Journal of Orthodontics. 2010; 15(1):107-17.

13. Iber C, Ancoli-Israel S, Chesson A, Quan SF. The AASM manual for the Scoring of Sleep and Associated Events: Rules Terminology and Technical Specifications: American Academy of Sleep Medicine Westchester, IL; 2007.

14. Sutherland K, Deane SA, Chan AS, Schwab RJ, Ng AT, Darendeliler MA, et al. Comparative effects of two oral appliances on upper airway structure in obstructive sleep apnea. Sleep. 2011; 34(4):469-77.

15. Cossellu G, Biagi R, Sarcina M, Mortellaro C, Farronato G. Three-dimensional evaluation of upper airway in patients with obstructive sleep apnea syndrome during oral appliance therapy. J Craniofac Surg. 2015; 26(3):745-8.

16. Furuhashi A, Yamada S, Shiomi T, Sasanabe R, Aoki Y, Yamada $Y$, et al. Effective three-dimensional evaluation analysis of upper airway form during oral appliance therapy in patients with obstructive sleep apnoea. J Oral Rehabil. 2013; 40(8):582-9.

17. Gao XM, Zeng XL, Fu MK, Huang XZ. Magnetic resonance imaging of the upper airway in obstructive sleep apnea before and after oral appliance therapy. Chin J Dent Res. 1999; 2(2):2735.

18. Marcussen L, Henriksen JE, Thygesen T. Do Mandibular Advancement Devices Influence Patients' Snoring and Obstructive Sleep Apnea? A Cone-Beam Computed Tomography Analysis of the Upper Airway Volume. J Oral Maxillofac Surg. 2015; 73(9):1816-26.

19. Ogawa T, Long J, Sutherland K, Chan AS, Sasaki K, Cistulli PA. Effect of mandibular advancement splint treatment on tongue shape in obstructive sleep apnea. Sleep Breath. 2015; 19(3):85763.

20. Sam K, Lam B, Ooi CG, Cooke M, Ip MS. Effect of a nonadjustable oral appliance on upper airway morphology in obstructive sleep apnoea. Respir Med. 2006; 100(5):897-902.

Publish in International Archives of Medicine

International Archives of Medicine is an open access journal publishing articles encompassing all aspects of medical science and clinical practice. IAM is considered a megajournal with independent sections on all areas of medicine. IAM is a really international journal with authors and board members from all around the world. The journal is widely indexed and classified Q2 in category Medicine. 